Article

\title{
Phycocyanin Protects Against UVB-Induced Apoptosis Through the PKC $\alpha / \beta$ II-Nrf-2/HO-1 Dependent Pathway in Human Primary Skin Cells
}

\author{
Ki Mo Kim ${ }^{1,2}$, Joo Young Lee ${ }^{1}{ }^{(\mathbb{D}}$, A-Rang $\operatorname{Im}^{1}$ and Sungwook Chae ${ }^{2, *}$ \\ 1 KM Convergence Research Division, Korea Institute of Oriental Medicine, 1672 Yuseong-daero, Yuseong-gu, \\ Daejeon 34054, Korea; vsrc@kiom.re.kr (K.M.K.); jy0130@kiom.re.kr (J.Y.L.); lar747@kiom.re.kr (A.-R.I.) \\ 2 Department of Korean Life Science and Technology, Korea University of Science and Technology, \\ Daejeon 34113, Korea \\ * Correspondence: kendall@kiom.re.kr; Tel.: +82-42-868-9524; Fax: +82-42-868-9301
}

Received: 23 November 2017; Accepted: 20 February 2018; Published: 22 February 2018

\begin{abstract}
Phycocyanin (Pc) is one of the active pigment constituents of Spirulina microalgae. It has been used for its potent antioxidant and anti-inflammatory properties. However, the protective effects of Pc against ultraviolet-B (UVB)-induced primary skin cells damage are still undefined. In the present study, we investigated whether Pc prevented UVB-induced apoptotic cell death in human dermal fibroblasts (HDF) and human epidermal keratinocytes (HEK). Pc induced the transcription of heme oxygenase-1 (HO-1). Furthermore, Pc treatments resulted in a marked increase in nuclear factor erythroid-derived 2 (NF-E2)-like 2 (Nrf-2) nuclear translocation. Also, Pc protected UVB induced apoptosis and reduced the p53 and Bax levels, as well as caspase- 3 activation. Pc treatment showed a significantly enhanced effect on the phosphorylation of protein kinase $C$ (PKC) $\alpha / \beta$ II, but not that of p38 mitogen-activated protein kinase (MAPK) or Akt. Induction of HO-1 induced by Pc was suppressed by Go6976, a selective inhibitor of PKC $\alpha / \beta$ II. In addition, knockdown of HO-1 by small interfering (siRNA) caused a significant increase in poly (ADP-ribose) polymerase 1 (PARP-1) cleavage and caspase- 3 activation after Pc pretreatment. Taken together, our results demonstrate that Pc-induced expression of HO- 1 is mediated by the PKC $\alpha / \beta$ II-Nrf-2/HO- 1 pathway, and inhibits UVB-induced apoptotic cell death in primary skin cells.
\end{abstract}

Keywords: phycocyanin; heme oxygenase-1; nuclear factor erythroid-derived 2 (NF-E2)-like 2; apoptosis

\section{Introduction}

Phycocyanin (Pc), a major pigment constituent of the phycobilisomes in Spirulina, has been suggested to exhibit radical scavenging properties [1], to reduce inflammatory responses [2,3], and reduce oxidative stress [1,4]. This phycobili protein enhances wound healing [5], retards platelet aggregation [6,7] and acts as a photodynamic agent to eradicate cancer cells in vitro [8,9]. Although the pharmaceutical effects of Pc have been reported, the mechanism underlying its anti-apoptotic effects is still poorly defined.

Ultraviolet radiation (UV) is divided into UVC (200-280 nm), UVB (280-320 nm), and UVA (320-400 nm). UVB is physiologically significant, penetrating into the papillary area of the dermis and inducing DNA damage in residing dendritic cells (DC) [10-12], and keratinocytes. These cells are perturbed both phenotypically and functionally, undergoing apoptosis upon exposure to UVB. Apoptosis can be induced in the region that suffers the greatest exposure, and surrounding cells can be partially damaged $[10,12]$. Apoptosis is the process of programmed cell death, which involves a series of morphological changes, including cell detachment, cell shrinkage, chromatin condensation and DNA 
fragmentation. This process is controlled by the balance between pro-apoptotic and anti-apoptotic signaling pathways [13].

Heme oxygenase-1 (HO-1) is the rate-limiting enzyme in the oxidative degradation of heme into bilirubin, iron, and carbon monoxide (CO). HO-1 has anti-inflammatory ability and is an important molecule in the host defense against oxidative stress [14]. HO-1 deficient mice exhibit a phenotype of an increased inflammatory state [15]. Exogenous administration of HO-1 by gene transfer protected lung cells from free radical-induced lethality and exhibited anti-inflammatory effects in the lungs [16]. It is important to substantiate this interesting property of the phytochemical Pc or other phytochemicals. There are several reports regarding HO- 1 induction by Pc $[17,18]$. In the transcriptional regulation of antioxidant proteins, $\mathrm{HO}-1$ and $\mathrm{NAD}(\mathrm{P}) \mathrm{H}$ :quinone oxidoreductase (NQO-1) are regulated by nuclear factor erythroid-derived 2 (NF-E2)-like 2 (Nrf-2), which is repressed by its negative regulator kelch-like ECH-associated protein 1 (Keap1) [19].

It has been reported that activation of Nrf-2 and the subsequent transcription of Nrf-2-related antioxidant proteins confers photoprotection response by inhibiting pro-inflammatory cytokines [20]. Nrf-2 protein might be phosphorylated by several signal transduction pathways, including the mitogen-activated protein kinase (MAPK), phosphoinositide 3-kinase (PI3K)/Akt, protein kinase $C$ (PKC), and extracellular signal-regulated kinase (ERK) pathways [21]. Several studies have suggested that the mechanisms of HO-1 induction involve pathways of MAPK, PI3K/Akt and Nrf-2 pathways [22-24]. Nrf-2 is known to induce expression of HO-1, and the inhibitory effect of HO-1 on UVB-mediated apoptotic cell death has been suggested earlier in UV-irradiated mice in which the inhibition of $\mathrm{HO}-1$ enzyme activity by the substrate antagonist protoporphyrin-tin ( $\mathrm{SnPP}$ ) was found to increase epidermal apoptotic cell numbers and upregulation of nuclear Nrf2 [25,26].

We hypothesized that Pc induces HO-1 expression via the Nrf-2 pathway in primary skin cells to protecting against UVB-mediated apoptosis. Thus, in this study, we determined whether Pc regulates the Nrf-2/HO-1 activation and whether the cytoprotective effect of Pc on the UVB-induced cell death requires HO-1 expression in human dermal fibroblasts (HDF) and human epidermal keratinocytes (HEK). We further explored whether Pc exerts its cytoprotective effect against UVB-induced cell death via the PKC $\alpha / \beta$ II dependent activation of the Nrf-2/HO-1 signaling pathway.

\section{Results}

\subsection{Pc-Induces HO-1 mRNA and Protein Expression without Cytotoxicity in Human Primary Skin Cells}

The molecular structure of $\mathrm{Pc}_{\mathrm{c}}$ is shown in Figure 1. We first examined whether Pc is cytotoxic, and found that Pc is not cytotoxic since doses up to $20 \mu \mathrm{g} / \mathrm{mL}$ did not alter the cell viability in HDF and HEK (Figure 2A). We next assessed whether Pc can induce HO-1, poly (ADP-ribose) polymerase-1 (PARP-1) expression in primary skin cells. Pc increased HO-1 mRNA and protein levels in a concentration-dependent and time-dependent manner in both HDF and HEK. However, Pc did not show any effect on PARP-1 cleaved form (Figure 2B,C, respectively). In addition, we examined DNA protection by Pc. These was no significant difference between the control and Pc-treated cells (Figure 1D). These results indicate that Pc-induced HO-1 expression at the mRNA and protein levels in human primary skin cells without cytotoxicity and Pc alone did not induce a typical apoptotic response in HEKs.

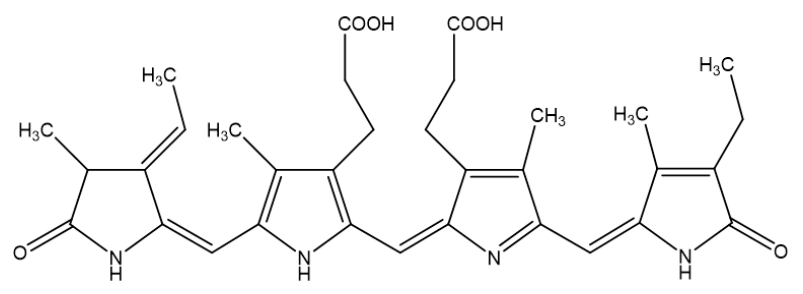

Figure 1. Chemical structure of phycocyanin (Pc). 
HDF

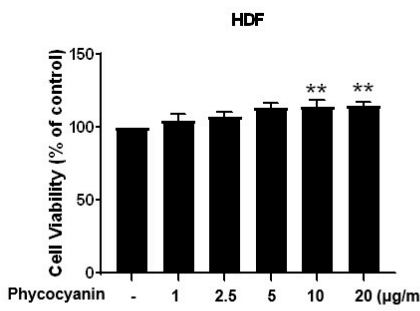

HEK

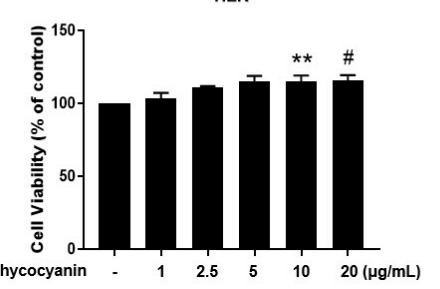

HDF

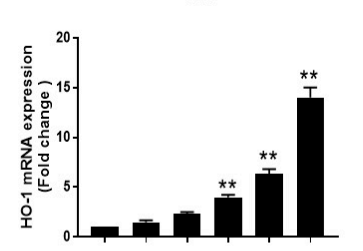

$\begin{array}{lllllllllll}1 & 2.5 & 5 & 10 & 20(\mu \mathrm{gg} / \mathrm{mL})^{\text {Phycocyanin }} & - & 1 & 2.5 & 5 & 10 & 20(\mu \mathrm{g} / \mathrm{mL})\end{array}$

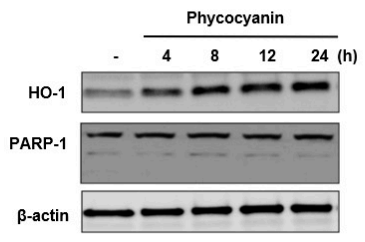

c

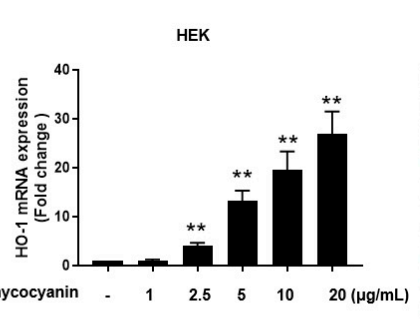

D

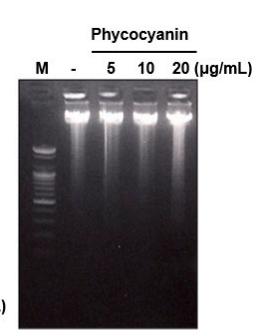

Figure 2. Effect of Pc on cell viability and HO-1 expression in primary skin cells. (A) HDF and HEK cells viabilities were assessed using the (3-(4,5-dimethylthiazol-2-yl)-2,5-diphenyltetrazolium bromide) MTT assay. Cells were incubated with Pc at the indicated concentration for $24 \mathrm{~h}$ intervals, followed by incubation with MTT solution for $2 \mathrm{~h}$. Each value is expressed as mean \pm standard deviation (SD) $(n=3)$; (B) Total RNAs was extracted from HDF after dose-dependent treatment with Pc for $8 \mathrm{~h}$. real time-quantification polymerase chain reaction (RT-qPCR) was performed with the HO-1 primers listed in the 'Materials and Methods' (top panel). Indicated time-dependent treatment with Pc (low panel). Expression of HO-1, poly (ADP-ribose) polymerase-1 (PARP-1), and $\beta$-actin were detected by western blotting. Each value is expressed as mean $\pm \mathrm{SD}(n=3)$; (C) HEK cells were treated with different concentration of Pc for $8 \mathrm{~h}$ (mRNA level) or treated with Pc for different times (protein level). Expression of HO-1, PARP-1, and $\beta$-actin were detected by western blotting; (D) HEK cells were treated with different concentration of Pc for $24 \mathrm{~h}$ DNA fragmentation analysis was performed with the 'Material and Methods' Data were obtained from three independent experiments and are expressed as the means $\pm \mathrm{SD},{ }^{* *} p<0.01$ versus the respective control groups. HO- 1 , heme oxygenase- 1 ; HDF, human dermal fibroblasts; HEK, human epidermal keratinocytes.

\subsection{Pc-Induced HO-1 Expression Is Mediated by Nrf-2}

Nrf2 translocates to the nucleus where it interacts with the antioxidant response element (ARE) to induce ARE-mediated antioxidant genes, including HO-1 [27]. Therefore, we attempted to examine the nuclear accumulation of Nrf-2 protein in Pc-stimulated primary skin cells. The nuclear levels of Nrf-2 were increased by treatment with $\mathrm{Pc}$ in a concentration-dependent manner while the cytosolic Nrf-2 was decreased. (Figure 3A,B upper panel). In addition, Pc treatment significantly increased expression of HO-1 (Figure 3A,B lower panel). Additionally, a luciferase reporter gene assay was performed in HEK. Cells were transfected with luciferase cDNAs under transcriptional control of an ARE. As a result, Pc was shown to significantly activate ARE-mediated transcriptional (Figure 3C). This indicates that the Pc activated both the Nrf2/ARE pathway system. 

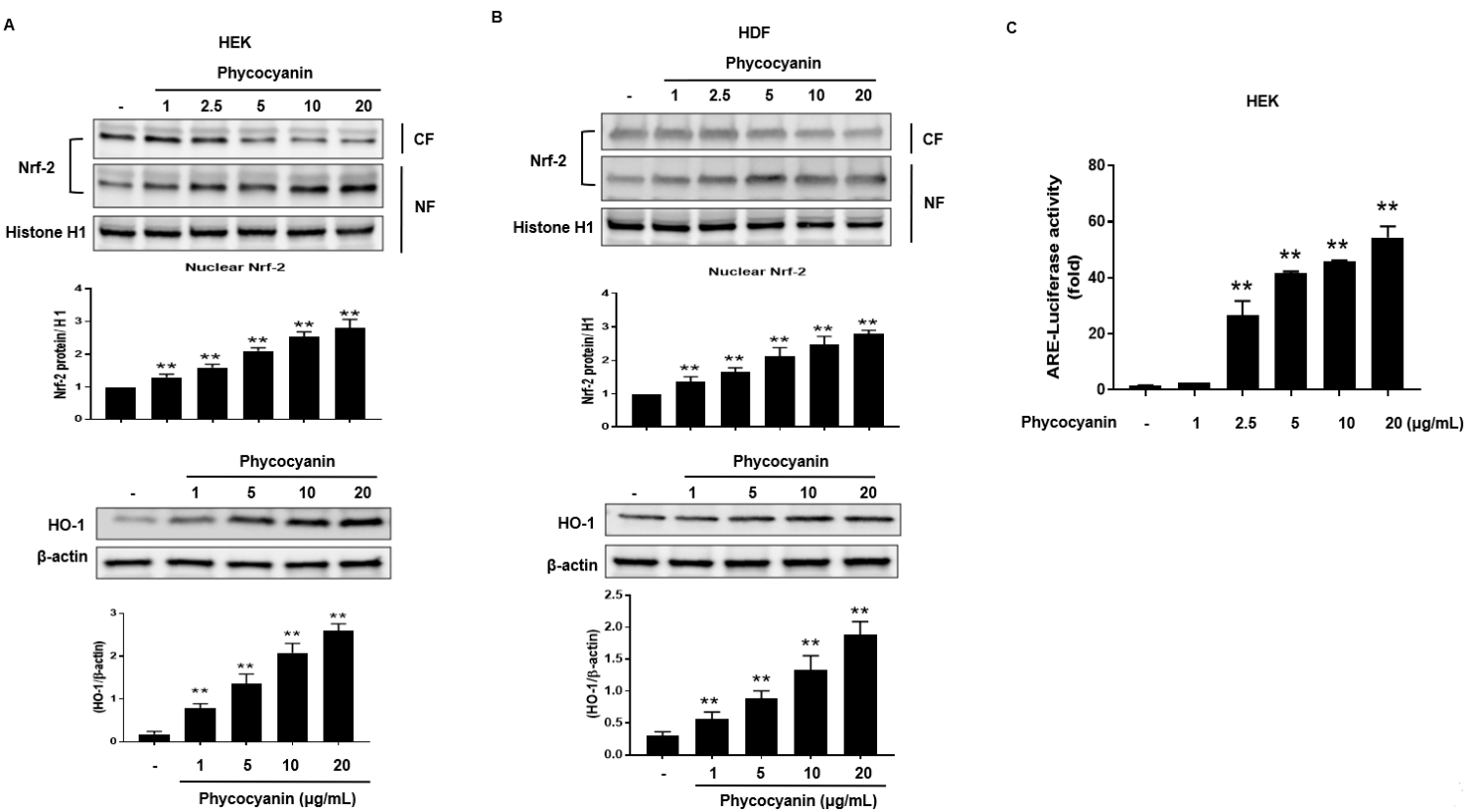

Figure 3. Pc-induced expression of HO-1 is mediated by Nrf-2. (A) HEK cells were treated with different concentrations of Pc for $6 \mathrm{~h}$, and then nuclear fractions (NF) and cytosolic fractions (CF) were prepared and analyzed by western blotting analysis (upper panel). HEK were treated with different concentration of Pc for $24 \mathrm{~h}$. Expression of HO-1 and $\beta$-actin was detected by western blotting (lower panel); (B) HDF cells treated with different concentration of Pc for $6 \mathrm{~h}$, and then nuclear fractions (NF) and cytosolic fractions (CF) were analyzed by western blotting analysis (upper panel). HDF were treated with varying concentration of Pc for $24 \mathrm{~h}$. (low panel). Expression of Nrf-2, HO-1, and $\beta$-actin were detected by specific antibodies (lower panel); (C) HEK cells were transfected with plasmid DNA (ARE-luciferase construct). Cells were allowed to recover for $24 \mathrm{~h}$. Subsequently, cells were treated with different concentration of Pc for $6 \mathrm{~h}$, and subjected to luciferase assays. Data were obtained from three independent experiments and are expressed as the means $\pm \mathrm{SD},{ }^{* *} p<0.01$ versus the respective control groups. Nrf-2, nuclear factor erythroid-derived 2 (NF-E2)-like 2; ARE, antioxidant response element.

\subsection{Pc Protects against UVB-Induced Apoptotic Cell Death in Primary Skin Cells}

Primary keratinocytes were pretreated with varying concentration of Pc followed by treatment with or without UVB $\left(20 \mathrm{~mJ} / \mathrm{cm}^{2}\right)$. Cells viability was assessed using the MTT (3-(4,5-dimethylthiazol-2-yl)-2,5-diphenyltetrazolium bromide) assay; Pc pretreatment was shown to markedly protect the UVB-exposed cells (Figure 4A). Additionally, we analyzed the expression of p53, Bax, Bcl-2, and caspase-3 in the keratinocytes cells. In our results, Pc significantly decreased p53, Bax/Bcl-2 expression levels, and Pc suppressed the activation of caspase-3 compared with that in cells exposed to UVB only (Figure 4B,C). Apoptotic chromatin condensation and DNA fragmentation (as indicated by terminal deoxynucleotidyl transferase dUTP nick end-labeling (TUNEL) staining, which were increased by UV exposure, were blocked by the addition of Pc (Figure 4D). These results indicate that Pc exhibited a protective effect against UVB-induced apoptotic cell death. 
A
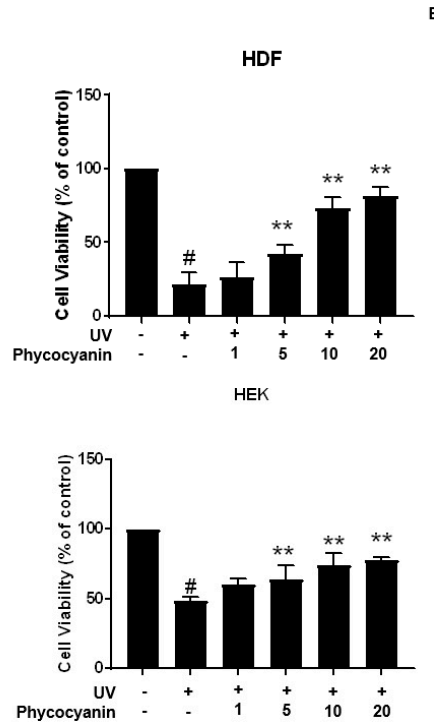

B
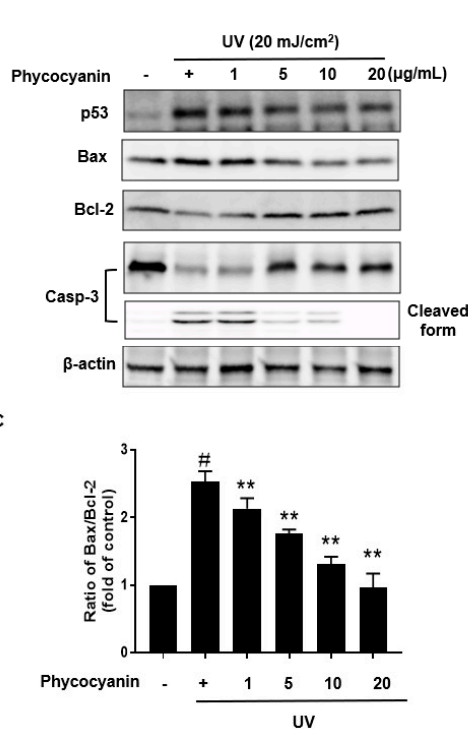
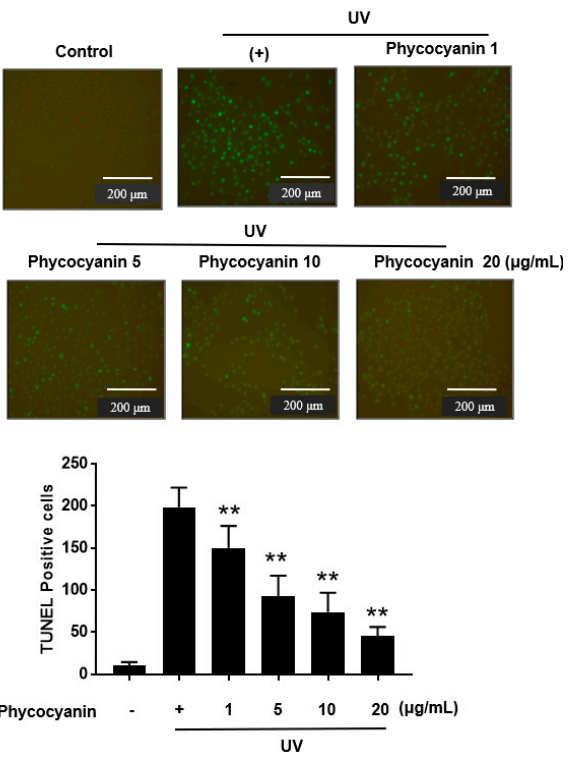

Figure 4. Cytoprotective effect Pc against UVB-induced apoptosis. (A) HDF and HEK cells were pretreated with different concentrations of $P_{C}$ for $24 \mathrm{~h}$ and then washed with phosphate-buffered saline (PBS). In PBS, the cells were exposed to UVB $\left(20 \mathrm{~mJ} / \mathrm{cm}^{2}\right)$ for $20 \mathrm{~min}$, and then incubated in normal medium for $2 \mathrm{~h}$. Viability of cells under different treatments was examined by an MTT assay and is expressed as a percentage of the control cells; (B). Cells were preincubated with the indicated concentration of Pc for $24 \mathrm{~h}$ and then washed with PBS. The cells were exposed to UVB radiation $\left(20 \mathrm{~mJ} / \mathrm{cm}^{2}\right)$ in PBS for $20 \mathrm{~min}$, and then incubated in normal medium for $2 \mathrm{~h}$. Western blotting analysis using anti-p53, Bax, Bcl-2, caspase-3-specific antibodies was performed; (C) HEK cells were pretreated with the Pc $(20 \mu \mathrm{g} / \mathrm{mL})$ for $24 \mathrm{~h}$, exposed to UVB light $\left(20 \mathrm{~mJ} / \mathrm{cm}^{2}\right)$ for $20 \mathrm{~min}$, and then incubated for $4 \mathrm{~h}$. Apoptotic cells were detected by the TUNEL assay and quantified. Each value is expressed as mean $\pm \mathrm{SD}(n=3) .{ }^{\#} p<0.05$ versus the control groups. ${ }^{* *} p<0.01$ indicates significant difference versus UVB light.

\subsection{Induction of HO-1 and Activation of Nrf-2 by Pc via Phosphorylation of PKC $\alpha / \beta$ II}

To further elucidate the upstream signaling pathway involved in Pc-mediated Nrf-2 activation and induction of HO-1, we examined the effect of Pc on p38, Akt and PKC $\alpha / \beta$ II. Phosphorylation of p38 and Akt was not detected in cells treated with Pc. However, Pc treatment was able to enhance the phosphorylation of PKC $\alpha / \beta$ II (Figure 5A). We also, confirm the involvement of PKC $\alpha / \beta$ II in the Nrf2 nuclear translocation for Pc induced HO-1 expression. We tested the phosphorylation pattern of PKC $\alpha / \beta$ II and Nrf2, nuclear translocation of Nrf2, and HO-1 expression after pretreatment with Go6976, a selective inhibitor of PKC $\alpha / \beta$ II. Inhibition of PKC $\alpha / \beta$ II activity significantly suppressed the phosphorylation and nuclear translocation of $\mathrm{Nrf} 2$, and $\mathrm{HO}-1$ expression, induced by Pc treatment (Figure 5B). We further confirmed the activation of ARE after treatment with Pc. Pc treated with increased ARE transcriptional element, however pretreatment with Go6976 was decreased ARE-luciferase activity (Figure 5C). In addition, we further examined the change in HO-1 expression with transfection of HO-1 small interfering RNA (siRNA). Pc protected against UVB-induced PARP-1 (apoptosis marker) and caspase-3 cleavage, in cells transfected with control RNA, but not in cells transfected with HO-1 siRNA (Figure 5D). These results suggest that Pc modulates HO-1 induction and Nrf-2 nuclear translocation via the PKC $\alpha / \beta$ II pathway, resulting in anti-apoptotic activity. 
A
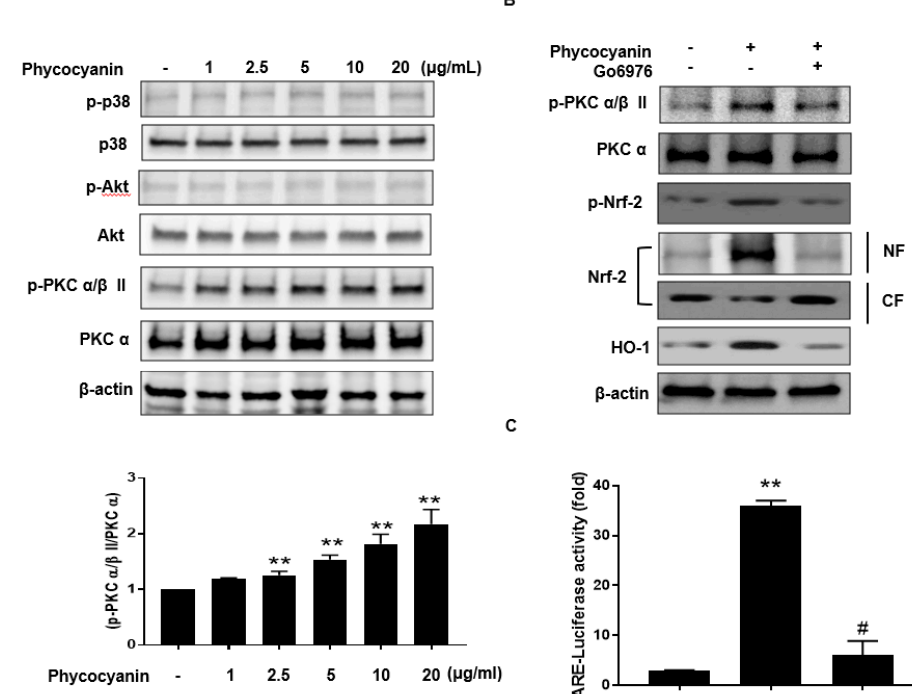

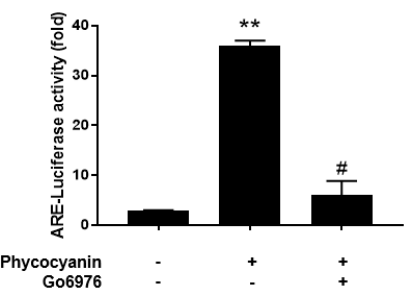

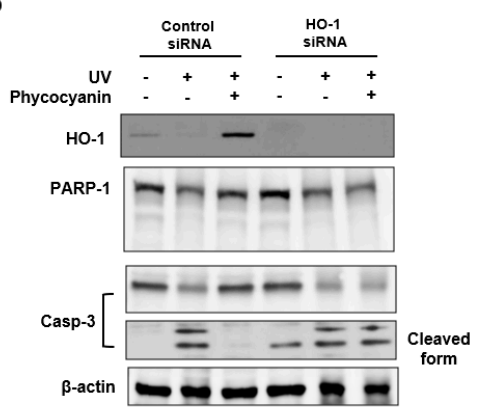

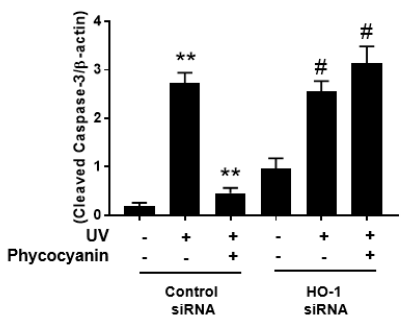

Figure 5. Pc activates HO-1 expression through a protein kinase $\mathrm{C}(\mathrm{PKC}) \alpha / \beta$ II-dependent pathway in primary skin cells. (A) HEK cells were treated with varying concentration of Pc for $4 \mathrm{~h}$. Cell lysates were analyzed by western blotting. Band densities of phospho-PKC $\alpha / \beta$ II were normalized to those of total PKC $\alpha$; (B) Cells were preincubated for 30 min with Go6976 $(2 \mu \mathrm{M})$ and then treated with Pc $(20 \mu \mathrm{g} / \mathrm{mL})$ for $12 \mathrm{~h}$, and then NF and CF were analyzed by western blotting; (C) Cells were transfected with control siRNA or HO-1 siRNA, and then cells were allowed to recover for $24 \mathrm{~h}$. The transfected cells were preincubated with Go6976 $(2 \mu \mathrm{M})$ for $1 \mathrm{~h}$, and then treated with Pc for $18 \mathrm{~h}$, subjected to luciferase assays; (D) Cells were transfected with control siRNA or HO-1 siRNA for $12 \mathrm{~h}$. The transfected cells were preincubated with Pc $(20 \mu \mathrm{g} / \mathrm{mL})$ for $24 \mathrm{~h}$, exposed to UVB light $\left(20 \mathrm{~mJ} / \mathrm{cm}^{2}\right)$ for $20 \mathrm{~min}$, and then incubated for $2 \mathrm{~h}$. Cell lysates were analyzed by western blotting. Data shown in the graphs are expressed as means $\pm \mathrm{SD}$ of three independent experiments. ${ }^{* *} p<0.01$ versus the control groups. \# $p<0.05$ versus the Pc-treated groups.

\section{Discussion}

Previous research has shown that Pc (Figure 1) exhibits antioxidative, anti-inflammatory, hepatoprotective and neuroprotective effects that have been demonstrated both in in vitro and in vivo studies [28-32], at least in part by providing energy repletion to UV-irradiated cells to ameliorate apoptosis and cellular energy loss [33,34]. However, the precise molecular mechanisms underlying the cytoprotective and anti-apoptotic effects remain largely unknown. The present study was undertaken to investigate the anti-apoptotic effects of Pc, and its underlying mechanisms. We found that induction of HO-1 expression by Pc resulted from transcriptional activation (Figure 2). Furthermore, Pc was able to significantly increase the nuclear accumulation of Nrf-2 and ARE-mediated transcriptional activity (Figure 3).

UVB irradiation triggers cytotoxic damage to the skin, which interferes with the normal cellular function, and finally culminates in photodamage, photoaging, and photocarcinogenesis [35]. Furthermore, UVB is known to be the most potent mutagenic component causing direct damage to cellular DNA as well as production of reactive oxygen species (ROS) in the epidermis, dermis [36,37]. Indeed, UVB represent carcinogenesis occurs via mutagenic DNA modification in susceptible cells due to insufficient repair and pathological enforcement of survival pathway and / or cell death pathway. Particularly, the role of UVB in skin photo damages, including skin cancer, has been widely reported because of the increasing incidence of photo damages [38]. Furthermore, the apoptotic response directly indicates the degree of genetic damage. We assessed whether Pc could inhibit UVB-induced skin cells apoptosis. Cell viability and western blotting analysis further showed that Pc increased the 
expression of anti-apoptotic factors, such as Bcl-2, in the UVB-exposed cells, while simultaneously decreasing the expression of the pro-apoptotic factors, p53, Bax, and caspase-3 (Figure 4A,B). Moreover, TUNEL staining showed that Pc significantly decreased DNA fragmentation in the UVB-irradiated cells (Figure 4C).

The PI3K/Akt and MAPK pathways also have been reported to be involved in HO-1 expression [39-41] and in Nrf-2-dependent transcription [41]. PKC also phosphorylates Nrf-2 in the Keap1-interacting domain [42,43]. A correlation between ERK activation and Nrf-2-mediated antioxidant enzyme expression has been reported [44]. Our results suggest that the increased expression of HO-1 and nuclear translocation of Nrf-2 by Pc are associated with of PKC $\alpha / \beta$ II, but not p38, or AKT, phosphorylation in keratinocytes (Figure 5A). In addition, the selective inhibitor of PKC $\alpha / \beta$ II, Go6976, suppressed Pc-induced HO-1 expression (Figure 5B). Using siRNA knockdown of HO-1 expression, Pc inhibition of UVB-induced PARP-1 cleavage, was partially, but significantly, reversed (Figure 5C). Nrf-2, a bZIP transcription factor, is an essential ARE-binding factor involved in both constitutive and inducible expression of glutathione biosynthetic enzymes [45]. It has been proposed that Keap1 and Nrf-2 constitute a crucial sensor for oxidative stress and mediate a key step in the signaling pathway, leading to transcription activation by the Nrf-2 nuclear shuttling mechanism [46], and cytoprotective role of the Keap-1-Nrf2 pathway [47]. Our data show that Pc activates Nrf-2 translocation and ARE-mediated transcription activation in skin cells (Figure 3).

Nrf-2 has emerged as a promising molecular target for the pharmacological prevention of skin damage caused by UV exposure. Although UVB induced apoptotic cells death was suppressed by Pc, cell cycle arrest, lipids signaling pathway remain unclear. Our findings show that Pc significantly improves cells viability in UVB-irradiated primary skin cells, and suppresses that apoptosis activated by UVB (Figure 4). In addition, Pc-induced HO-1 expression suppresses UVB-induced PARP-1 cleavage, and caspase- 3 activation (Figure 5). These results suggested that $P c$ is able to attenuate UVB-induced apoptotic cell death in human dermal keratinocytes. Notably, the present study confirmed that these were mediated at least in part, via inducing PKC $\alpha / \beta$ II/Nrf-2-mediated HO-1 pathway. Further studies are required to investigate the in vivo anti UV effects of Pc.

\section{Material and Methods}

\subsection{Reagents}

Pc was purchased from Sigma-Aldrich, Inc. (St. Louis, MO, USA). Go6976, was purchased from Calbiochem Company (San Diego, CA, USA). HO-1 and control siRNAs were obtained from Santa Cruz Biotechnology (Dallas, TX, USA) and antibodies to p-PKC $\alpha / \beta$ II (\#9375), p-Akt (\#2971), PARP-1 (\#9542), p-p38 (\#9212), cleaved caspase-3 (\#9661), and $\beta$-actin (\#4967) were obtained from Cell Signaling Technology (Beverly, MA, USA). p-Nrf-2 (ab76026) was purchased from Abcam (Cambridge, UK). Nrf-2 (sc-722), histone-H1 (sc-393358), procaspase-3 (H-277), and HO-1 (sc-10789) antibodies were purchased from Santa Cruz Biotechnology. All other reagents were purchased from Sigma-Aldrich unless otherwise indicated. Pc solutions was prepared in dimethyl sulfoxide (DMSO) and stored at $-20{ }^{\circ} \mathrm{C}$.

\subsection{Primary Cell Culture}

Primary HDF were obtained from ScienCell Research Laboratories (Carlsbad, CA, USA). HDF cells were propagated in fibroblast medium supplemented with $5 \%$ fetal bovine serum (FBS), $1 \%$ fibroblast growth supplement, and $1 \%$ penicillin and streptomycin (P/S). HEKs were purchased from Lonza (Walkersville, MD, USA) and maintained in KGM-Gold SingleQuots ${ }^{\mathrm{TM}}$ was purchased from Lonza medium kit containing supplements and growth factors. Both primary cultures were maintained in a humidified $5 \% \mathrm{CO}_{2}$ incubator at $37^{\circ} \mathrm{C}$. HDF and HEKs cells were purchased from each company are used for research application by informed consent or legal authorization. Their cells used passages 6 . Viabilities of HDF and HEK were assessed by an MTT assay as previously described [48]. 


\subsection{UVB Radiation}

Cells were pre-incubated with the indicated concentration of Pc for $24 \mathrm{~h}$, washed with PBS and exposed to a UVB $\left(20 \mathrm{~mJ} / \mathrm{cm}^{2}\right)$ light source using a UVP Cross linker (Ultra-Violet Products Ltd., Cambridge, UK) for 20 min Afterwards, the cells were washed with PBS, medium was added, and cells were further incubated for $2 \mathrm{~h}$.

\subsection{RNA Interference}

Small interfering RNAs (siRNA) against HO-1 and control siRNA (Santa Cruz Biotechnology) were transiently transfected into cells using Lipofectamine 2000 according to the manufacturer's instructions (Invitrogen, Carlsbad, CA, USA). Aliquots of $1 \times 10^{5}$ cells/well were plated in 6-well plates on the day before transfection and grown to approximately $70 \%$ confluence. The cells were then transfected with $100 \mathrm{nmol}$ of HO-1 siRNA or control siRNA plus $100 \mathrm{pmol}$ of Lipofectamine for $6 \mathrm{~h}$ in Opti-MEM ${ }^{\circledR}$ I reduced serum medium (Invitrogen). Following an incubation period of $24 \mathrm{~h}$, the protein levels were measured by western blot analysis.

\subsection{DNA Fragmentation Assay}

Pc was indicated concentration added, and the cells were incubated for $24 \mathrm{~h}$. The cells were re-suspended in lysis buffer ( $20 \mathrm{mM}$ Tris- $\mathrm{HCl}, \mathrm{pH}$ 8.0, $10 \mathrm{mM}$, ethylenediaminetetraacetic acid (EDTA), $0.2 \%$ Triton $\mathrm{X}-100$ ) containing $0.1 \mathrm{mg} / \mathrm{mL}$ proteinase $\mathrm{K}$ and $50 \mu \mathrm{g} / \mathrm{mL}$ RNase $\mathrm{A}$, and the samples were incubated at $37^{\circ} \mathrm{C}$ overnight. The DNA was subjected to electrophoresis using a $1.5 \%$ agarose gel. The agarose gel was stained with $1 \mu \mathrm{g} / \mathrm{mL}$ ethidium bromide in $0.5 \mathrm{X}$ tris-borate-EDTA (TBE) buffer to visualize the DNA fragmentation, and the gel was examined using photographs taken under UV light.

\subsection{Quantitative Reverse Transcription PCR (RT-qPCR)}

Total cellular RNA was extracted using Trizol reagent according to the manufacturer's instructions (Thermo Fisher Scientific, Waltham, MA, USA). To quantify the HO-1 gene expression in HDF and HEK cells were using the TaqMan Primers (Hs01110250_ml), RT-qPCR was performed with TaqMan ${ }^{\circledR}$ Universal PCR Master Mix (Applied Biosystems, Waltham, MA, USA) using the ABI QuantStudio $^{\mathrm{TM}} 6$ Flex Real-Time PCR system (Applied Biosystems). The relative mRNA expression levels of HO- 1 was normalized to that of $\beta$-actin. Each sample was assayed in triplicate and relative mRNA expression levels were calculated using the relative quantitation comparative CT method $(\Delta \Delta \mathrm{Ct}$ method).

\subsection{Preparation of Cytosolic and Nuclear Fractions}

Cytosolic and nuclear fractions were prepared using NE-PER ${ }^{\mathrm{TM}}$ Nuclear and Cytoplasmic Extraction Reagent Kit (Thermo Fisher Scientific). Briefly, cells were trypsinized and suspended in cell fractionation buffer for $5 \mathrm{~min}$. The suspension was centrifuged at $500 \times \mathrm{g}$ for $5 \mathrm{~min}$ at $4{ }^{\circ} \mathrm{C}$ and the supernatant containing the cytoplasmic fraction was collected. The pellet containing the nuclear fraction was re-suspended in ice-cold cell disruption buffer, vortexed, and incubated for $5 \mathrm{~min}$ on ice to ensure complete nuclear protein extraction. Nuclear Nrf-2 was detected by western blotting.

\subsection{Western Blotting}

After, different treatments, the cell lysates were prepared from HDF and HEK $\left(5 \times 10^{6}\right)$ in $1 \times$ Laemmli lysis buffer (2.4 M glycerol, $0.14 \mathrm{M}$ Tris- $\mathrm{HCl}$ (pH 6.8), $0.21 \mathrm{M}$ sodium dodecyl sulfate (SDS), and $0.3 \mathrm{mM}$ bromophenol blue), and boiled for $10 \mathrm{~min}$. The protein content was measured using the BCA Protein Assay Reagent (Pierce, Waltham, MA, USA). Protein samples $(20 \mu \mathrm{g})$ were diluted with $1 \times$ lysis buffer, separated by SDS-polyacrylamide gel electrophoresis, and transferred onto polyvinylidene fluoride membranes (PVDF). The membranes were then incubated with primary antibodies against Nrf-2 (1:1000), HO-1(1:1000), histone H1 (1:1000), p53 (1:1000), Bax (1:1000), Bcl-2 (1:1000), procaspase-3 
(1:1000), cleavage caspase-3 (1:1000), and $\beta$-actin (1:1000). Subsequently, the membranes were washed, incubated with horseradish peroxidase-conjugated secondary antibodies, washed again, and detected using an enhanced chemiluminescence detection system from Amersham Bioscience (Buckinghamshire, UK). Protein expression levels were determined by analysis of the signals that were captured using an image analyzer (Las-3000, Fujifilm, Tokyo, Japan).

\subsection{ARE-Luciferase Assay}

The effects of Pc on ARE activity were assayed using a Luciferase Reporter Assay System (SABiosciences, Frederick, MD, USA). Briefly, HEK cells were seeded at a density of $1 \times 10^{5}$ cells / well in 6-well plates and grown to $60-70 \%$ confluence. Cells were then transfected with $100 \mathrm{ng}$ of ARE luciferase reporter construct using Lipofectamine ${ }^{\mathrm{TM}} 2000$ transfection reagent according to the manufacturer's protocol (Invitrogen). Renilla-CMV-Renilla luciferase was used to correct for variations in transfection efficiency. Twelve hours after transfection, cells were treated with the Pc for $24 \mathrm{~h}$. After incubation, cells were lysed was carried out using the reporter lysis buffer. Cell extracts were then mixed with a luciferase substrate (Promega, Madison, WI, USA), and luciferase activity was measured using a Tristar LB 941 multimode microplate reader (Tristar, Berthold, Wildbad, Germany).

\subsection{Evaluation of Apoptotic Cell Death}

HEK cells were plated at $1 \times 10^{5}$ cells $/ \mathrm{mL}$ in chamber slides. Cells were pretreated with Pc for $24 \mathrm{~h}$, washed with PBS and then exposed to a UVB radiation $\left(20 \mathrm{~mJ} / \mathrm{cm}^{2}\right)$ for $20 \mathrm{~min}$ Afterwards, the cells were washed with PBS, medium was added, and cells were further incubated for 4 hours. And found to induce apoptosis was assessed by a fluorescence TUNEL assay kit according to the manufacturer's recommendations (Roche-Applied Science, Indianapolis, IN, USA). Images were captured using an inverted-fluorescence microscope (Olympus IX71, Tokyo, Japan). At least 100 TUNEL-positive cells were scored for each experiment performed in triplicate.

\subsection{Statistical Analysis}

The data are presented as the means \pm standard deviations (SD) of at least three separate experiments. Comparisons between two groups were made using the Student's $t$-test provided in the Graph Pad software version 5 (Graph Pad Software, La Jolla, CA, USA); significance was established at $p<0.05$.

Acknowledgments: This work was supported by grants (K17300) from the Korea Institute of Oriental Medicine (KIOM).

Author Contributions: K.M.K. and S.C. designed the experiments and wrote the paper; J.Y.L. and A.-R.I. performed the experiments. All authors participated in collecting data, and analyzing data and preparing the manuscript, and all authors approved the final version of the manuscript for publication.

Conflicts of Interest: The authors declare no conflict of interest.

\section{References}

1. Zhou, Z.P.; Liu, L.N.; Chen, X.L.; Wang, J.X.; Chen, M.; Zhang, Y.Z.; Zhou, B.C. Factors that affect antioxidant activity of C-phycocyanins from Spirulina platensis. J. Food. Biochem. 2005, 29, 313-322. [CrossRef]

2. Cherng, S.C.; Cheng, S.N.; Tarn, A.; Chou, T.C. Anti-inflammatory activity of c-phycocyanin in lipopolysaccharide-stimulated RAW 264.7 macrophages. Life Sci. 2007, 81, 1431-1435. [CrossRef] [PubMed]

3. Manconia, M.; Pendás, J.; Ledón, N.; Moreira, T.; Sinico, C.; Saso, L.; Fadda, A.M. Phycocyanin liposomes for topical anti-inflammatory activity: In vitro in vivo studies. J. Pharm. Pharmacol. 2009, 61, 423-430. [CrossRef] [PubMed]

4. Li, X.L.; Xu, G.; Chen, T.; Wong, Y.S.; Zhao, H.L.; Fan, R.R.; Gu, X.M.; Tong, P.C.; Chan, J.C. Phycocyanin protects INS-1E pancreatic beta cells against human islet amyloid polypeptide-induced apoptosis through attenuating oxidative stress and modulating JNK and p38 mitogen-activated protein kinase pathways. J. Biochem. Cell Biol. 2009, 41, 1526-1535. [CrossRef] [PubMed] 
5. Madhyastha, H.K.; Radha, K.S.; Nakajima, Y.; Omura, S.; Maruyama, M. uPA dependent and independent mechanisms of wound healing by C-phycocyanin. J. Cell. Mol. Med. 2008, 12, 2691-2703. [CrossRef] [PubMed]

6. Chiu, H.F.; Yang, S.P.; Kuo, Y.L.; Lai, Y.S.; Chou, T.C. Mechanisms involved in the antiplatelet effect of C-phycocyanin. Br. J. Nutr. 2006, 95, 435-440. [CrossRef] [PubMed]

7. Hsiao, G.; Chou, P.H.; Shen, M.Y.; Chou, D.S.; Lin, C.H.; Sheu, J.R. C-phycocyanin, a very potent and novel platelet aggregation inhibitor from Spirulina platensis. J. Agric. Food. Chem. 2005, 53, 7734-7740. [CrossRef] [PubMed]

8. Li, B.; Chu, X.; Gao, M.; Li, W. Apoptotic mechanism of MCF-7 breast cells in vivo and in vitro induced by photodynamic therapy with C-phycocyanin. Acta Biochim. Biophys. Sin. (Shanghai) 2010, 42, 80-89. [CrossRef] [PubMed]

9. Wang, Y.; Cai, C.; Li, B.; Liu, C.; He, P. Photodynamic effect of two kinds of phycobiliproteins on human liver cancer cell line SMMC-7721 in vitro. Sheng Wu Gong Cheng Xue Bao 2009, 25, 1417-1423. [PubMed]

10. Meunier, L. Ultraviolet light and dendritic cells. Eur. J. Dermtol. 1999, 9, 269-275.

11. Kolgen, W.; Both, H.; Van Weelden, H.; Guikers, K.L.; Brujinzeel-Koomen, C.A.; Knol, E.F.; Van Vloten, W.A.; De Gruijl, F.R. Epidermal langerhans cell depletion after artificial ultraviolet B irradiation of human skin in vivo: Apoptosis versus migration. J. Investig. Dermatol. 2002, 118, 812-817. [CrossRef] [PubMed]

12. Nakagawa, S.; Ohtani, T.; Mizuashi, M.; Mollah, Z.U.; Ito, Y.; Tagami, H.; Aiba, S. p38 Mitogen-activated protein kinase mediates dual role of ultraviolet $\mathrm{B}$ radiation in induction of maturation and apoptosis of monocyte-derived dendritic cells. J. Investig. Dermatol. 2004, 123, 361-370. [CrossRef] [PubMed]

13. McGowan, B.S.; Ciccimaro, E.F.; Chan, T.O.; Feldman, A.M. The balance between pro-apoptotic and anti-apoptotic pathways in the failing myocardium. Cardivasc. Toxicol. 2003, 123, 361-370. [CrossRef]

14. Maines, M.D. Heme oxygenase: Function, multiplicity, regulatory mechanisms, and clinical applications. FASEB J. 1988, 2, 2557-2568. [CrossRef] [PubMed]

15. Wiesel, P.; Patel, A.P.; DiFonzo, N.; Marria, P.B.; Sim, C.U.; Pellacani, A.; Maemura, K.; LeBlanc, W.; Marino, K.; Doerschuk, C.M.; et al. Endotoxin-induced mortality is related to increased oxidative stress and end-organ dysfunction, not refractory hypotension, in heme oxygenase-1-deficient mice. Circulation 2000, 102, 3015-3022. [CrossRef] [PubMed]

16. Tu, C.F.; Kuo, C.H.; Juang, J.H. Effects of heme oxygenase-1 transgenic islets in transplantation. Transplant. Proc. 2005, 37, 3463-3467. [CrossRef] [PubMed]

17. Gao, Y.; Llu, C.; Wan, G.; Wang, X.; Cheng, X.; Ou, Y. Phycocyanin prevents methylglyoxal-induced mitochondrial-dependent apoptosis in INS-1 cells by Nrf2. Food Funct. 2016, 7, 1129-1137. [CrossRef] [PubMed]

18. Lee, S.Y.; Chen, P.Y.; Lin, J.C.; Kirkby, N.S.; Ou, C.H.; Chang, T.C. Melaleuca alternifolia Induces Heme Oxygenase-1 Expression in Murine RAW264.7 Cells through Activation of the Nrf2-ARE Pathway. Am. J. Chin. Med. 2017, 45, 1631-1648. [CrossRef] [PubMed]

19. De Vries, H.E.; Witte, M.; Hondius, D.; Rozermuller, A.J.; Drukarch, B.; Hoozemans, J.; Van Horssen, J. Nrf-2-induced antioxidant protection: A promising target to counteract ROS-mediated damage in neurodegenerative disease? Free Radic. Biol. Med. 2008, 45, 1375-1383. [CrossRef] [PubMed]

20. Lee, J.W.; Bae, C.J.; Choi, Y.J.; Kim, S.I.; Kwon, Y.S.; Lee, H.J.; Kim, S.S.; Chun, W. 3,4,5-trihydroxycinnamic acid inhibits lipopolysaccharide (LPS)-induced inflammation by Nrf2 activation in vitro and improves survival of mice in LPS-induced endotoxemia model in vivo. Mol. Cell. Biochem. 2014, 390, 143-153. [CrossRef] [PubMed]

21. Kim, J.K.; Jang, H.D. Nrf-2-mediated HO-1 induction coupled with the ERK signaling pathway contribute to indirect antioxidant capacity of caffeic acid phenethyl ester in HepG2 cell. Int. J. Mol. Sci. 2014, 15, 12149-12165. [CrossRef] [PubMed]

22. Chen, Y.C.; Shen, S.C.; Lee, W.R.; Lin, H.Y.; Ko, C.H.; Lee, T.J. Nitric oxide and prostaglandin E2 participate in lipopolysaccharide/interferon-gamma-induced heme oxygenase and prevents RAW264.7 macrophages from UV-irradiation-induced cell death. J. Cell. Biochem. 2002, 86, 331-339. [CrossRef] [PubMed]

23. Jiang, Y.; Chen, G.; Zheng, Y.; Lu, L.; Wu, C.; Zhang, Y.; Lin, Q.; Cao, X. TLR4 signaling induces functional nerve growth factor receptor $\mathrm{p} 75^{\mathrm{NTR}}$ on mouse dendritic cells via $\mathrm{p} 38$ MAPK and NF- $\mathrm{BB}$ pathways. Mol. Immunol. 2008, 45, 1557-1566. [CrossRef] [PubMed] 
24. Tseng, C.K.; Lin, C.K.; Chang, H.W.; Wu, Y.H.; Yen, F.L.; Chang, F.R.; Chen, W.C.; Yeh, C.C.; Lee, J.C. Aqueous extract of Gracilaria. tenuistipitata suppresses LPS-induced NF-KB and MAPK activation in RAW 264.7 and rat peritoneal macrophages and exerts hepatoprotective effects on carbon tetrachloride-treated rat. PLOS ONE 2014, 9, e86557. [CrossRef]

25. Ibuki, Y.; Allanson, M.; Dixon, K.D.; Reeve, V.E. Radiation sources providing increased UVA/UVB ratios attenuate the apoptotic effects of the UVB waveband UVA-dose-dependently in hairless mice. J. Investig. Dermatol. 2008, 127, 2236-2244. [CrossRef] [PubMed]

26. Yuan, X.Y.; Pang, X.W.; Zhang, G.Q.; Guo, J.Y. Salidroside's Protection Against UVB-Mediated Oxidative Damage and Apoptosis Is Associated with the Upregulation of Nrf2 Expression. Photomed. Laser Surg. 2017, 1, 49-56. [CrossRef] [PubMed]

27. Cho, H.Y.; Reddy, S.P.; Kleeberger, S.R. Nrf2 defends the lung from oxidative stress. Antioxid. Redox Signal. 2006, 8, 76-87. [CrossRef] [PubMed]

28. Romay, C.H.; Gonzalez, R.; Ledon, N.; Remiez, D.; Rimbau, V. C-phycocyanin: A biliprotein with antioxidant, anti-inflammatory and neuroprotective effects. Curr. Protein Pept. Sci. 2003, 4, 207-216. [CrossRef] [PubMed]

29. Eriksen, N.T. Production of phycocyanin-A pigment with applications in biology, biotechnology, foods and medicine. Appl. Microbiol. Biotechnol. 2008, 80, 1-14. [CrossRef] [PubMed]

30. Ou, Y.; Zheng, S.; Lin, L.; Jiang, Q.; Yang, X. Protective effect of C-phycocyanin against carbon tetrachloride-induced hepatocytes damage in vitro and in vivo. Chem. Biol. Interact. 2010, 185, 94-100. [CrossRef] [PubMed]

31. Chaiklahan, R.; Chirasuwan, N.; Loha, V.; Tia, S.; Bunnag, B. Separation and purification of phycocyanin from Spirulina sp. using a membrane process. Bioresour. Technol. 2011, 102, 7159-7164. [CrossRef] [PubMed]

32. Pentón-Rol, G.; Marín-Prida, J.; Pardo-Andreu, G.; Martínez-Sánchez, G.; Acosta-Medina, E.F.; Valdivia-Acosta, A.; Lagumersindez-Denis, N.; Rodríguez-Jiménez, E.; Llópiz-Arzuaga, A.; López-Saura, P.A.; et al. C-phycocyanin is neuroprotective against global cerebral ischemia/reperfusion injury in gerbils. Brain Res. Bull. 2011, 86, 42-52. [CrossRef] [PubMed]

33. Park, J.; Halliday, G.M.; Surjana, D.; Damian, D.L. Nicotinamide prevents ultraviolet radiation-induced cellular energy loss. Photochem. Photobiol. 2010, 86, 942-948. [CrossRef] [PubMed]

34. Damian, D.L. Photoprotective effects of nicotinamide. Photochem. Photobiol. Sci. 2010, 9, 578-585. [CrossRef] [PubMed]

35. Sander, C.S.; Chang, H.; Hamm, F.; Elsner, P.; Thiele, J.J. Role of oxidative stress and antioxidant network in cutaneous carcinogenesis. Int. J. Dermatol. 2004, 43, 326-335. [CrossRef] [PubMed]

36. Budden, T.; Bowden, N.A. The role of altered nucleotide excision repair and UVB-induced DNA damage in melanomagenesis. Int. J. Mol. Sci. 2013, 14, 1132-1151. [CrossRef] [PubMed]

37. Lee, C.H.; Wu, S.B.; Hong, C.H.; Yu, H.S.; Wei, Y.H. Molecular mechanisms of UV-induced apoptosis and its effect on skin residential cells; The implication in UV-based phototherapy. Int. J. Mol. Sci. 2013, 14, 6414-6435. [CrossRef] [PubMed]

38. Bowden, G.T. prevention of non-melanoma skin cancer by targeting ultraviolet-B-light signaling. Nat. Rev. Cancer 2004, 4, 25-35. [CrossRef] [PubMed]

39. Balogan, E.; Hoque, M.; Gong, P.; Killeen, E.; Green, C.J.; Foresti, R.; Alam, J.; Motterini, R. Curcumin activates the haem oxygenase- 1 gene via regulation of Nrf2 and the antioxidant-responsive element. Biochem. J. 2003, 371, 887-895. [CrossRef] [PubMed]

40. Gong, P.; Hu, B.; Cederbaum, A.I. Diallyl sulfide induces heme oxygenase-1 through MAPK pathway. Arch. Biochem. Biophys. 2004, 432, 252-260. [CrossRef] [PubMed]

41. Shen, G.; Hebbar, V.; Nair, S.; Xu, C.; Li, W.; Lin, W.; Keum, Y.S.; Han, J.; Gallo, M.A.; Kong, A.N. Regulation of Nrf2 transactivation domain activity. The differential effects of mitogen-activated protein kinase cascades and synergistic stimulatory effect of Raf and CREB-binding protein. J. Biol. Chem. 2004, 279, 23052-23060. [CrossRef] [PubMed]

42. Huang, H.C.; Nguyen, T.; Pickett, C.B. Regulation of the antioxidant response element by protein kinase C-mediated phosphorylation NF-E2-related factor 2. Proc. Natl. Acad. Sci. USA 2000, 97, 1275-1280. [CrossRef] [PubMed]

43. Huang, H.C.; Nguyen, T.; Pickett, C.B. Phosphorylation of Nrf2 at Ser40 by protein kinase C regulates antioxidant response element-mediated transcription. J. Biol. Chem. 2002, 277, 42769-42774. [CrossRef] [PubMed] 
44. Zipper, L.M.; Mulcahy, R.T. Erk activation is required for Nrf2 nuclear localization during pyrroidine dithiocarbamate induction of glutamate cysteine ligase modulatory gene expression in HepG2 cells. Toxicol. Sci. 2003, 73, 124-134. [CrossRef] [PubMed]

45. McMahon, M.; Itoh, K.; Yamamoto, M.; Chanas, S.A.; Henderson, C.J.; McLellan, L.I.; Wolf, C.R.; Cavin, C.; Hayes, J.D. The Cap ' $n$ ' Collar basic leucine zipper transcription factor Nrf2 (NF-E2 p45-related factor 2) controls both constitutive and inducible expression of intestinal detoxification and glutathione biosynthetic enzymes. Cancer Res. 2001, 61, 3299-3307. [PubMed]

46. Itoh, K.; Wakabayashi, N.; Katoh, Y.; Ishii, T.; Igarashi, K.; Engel, J.D.; Yamamoto, M. Keap1 represses nuclear activation of antioxidant responsive elements by Nrf2 through binding to the amino-terminal Neh2 domain. Genes Dev. 1999, 13, 76-86. [CrossRef] [PubMed]

47. Baird, L.; Dinkova-Kostova, A.T. The cytoprotective role of the Keap1-Nrf-2 pathway. Arch. Toxicol. 2011, 85, 241-272. [CrossRef] [PubMed]

48. Im, R.A.; Kim, Y.H.; Uddin, M.R.; Lee, H.W.; Chae, S.W.; Kim, Y.W.; Jung, W.S.; Kang, B.J.; Mun, C.S.; Lee, M.Y. Scutellaria baicalensis extracts and flavonoids protect Rat L6 Cells from antimycin A-induced mitochondrial dysfunction. Evid. Based Complement. Alternat. Med. 2012, 2012, 517965-517973. [CrossRef] [PubMed]

Sample Availability: not available. 